\title{
DIAGNOSA STATISTIK PEMETAAN PEMAHAMAN BAHASA PEMOGRAMAN SEBAGAI ACUAN UNTUK MEMPERSIAPKAN PENELITIAN MAHASISWA
}

\author{
Heri Herwanto \\ Fakultas Ilmu Komputer Universitas Kuningan \\ Jalan Tjut Nyak Dhien No. 36 A Cijoho Kuningan Jawa Barat 45513Telepon (0232) \\ 2875097Email : heri.herwanto@uniku.ac.id
}

\begin{abstract}
Pemetaan pemahaman bahasa pemograman mahasiswa merupakan hal yang sangat penting dalam memperlancar penyusunan skripsi. Penelitian ini bertujuan untuk memetakan pemahaman bahasa pemograman dihubungkan dengan peminatan penelitian, pembimbingan skripsi dan kebijakan lembaga. Metodologi yang digunakan adalah mixmethode dimana analisis dipaparkan secara kualitatif dan kuantitatif. Teknik analisis yang digunakan adalah analisis kuesioner dengan menggunakan skala likert dengan berbantuan software. Hasil analisis didapatkan mayoritas responden ada pada skala 3 sampai 4 yang artinya ada pada interval setuju dan sangat setuju serta dapat dikategorikan bernilai positif. Dengan adanya pemetaan pemahaman bahasa pemograman ini, dosen pembimbing dan pemangku kebijakan dapat memperoleh gambaran mengenai potensi mahasiswa untuk dikembangkan dalam mengahasilkan produk hasil skripsi dan mencetak kualitas lulusan yang berdaya saing.
\end{abstract}

Kata Kunci : Pemahaman Bahasa Pemograman, Peminatan dan pembimbingan skripsi

Mapping the understanding of student programming languages is very important in facilitating the preparation of the thesis. This study aims to map the understanding of programming languages associated with specialization in research, thesis guidance and institutional policy. The methodology used is a mix method where the analysis is presented qualitatively and quantitatively. The analysis technique used is questionnaire analysis using a Likert scale with software assistance. The results of the analysis found that the majority of respondents are on a scale of 3 to 4, which means that there are agreed and strongly agreed intervals and can be categorized as positive. With this mapping of understanding of the programming language, supervisors and policy makers can get an idea of the potential of students to be developed in producing thesis products and print competitive quality graduates.

Keywords: Understanding of Programming Language, Specialization and Thesis Guidance

\section{Pendahuluan}

Pesatnya sains dan teknologi telah mengubah pola pikir dan sudut pandang seseorang, kelompok atau organisasi yang ada di masyarakat dalam menyikapi segala permasalahan yang dihadapi pada kegiatan atau aktivitas sehari-hari. Pola pikir dan sudut pandang yang dibangun senantiasa harus diarahkan pada orientasi yang positip. Dalam menyikapi pesatnya sains dan teknologi, kita sebagai penerus generasi bangsa harus mempersiapkan diri kita dengan bekal keilmuan yang berkualitas melalui pendidikan formal maupun non formal.
Pendidikan yang digalakan pada masa sekarang cenderung lebih kepada pendidikan vokasi atau keahlian. Hal ini tidak bisa dipungkiri dikarenakan permasalahan dan fenomena yang muncul dalam masyarakat membutuhkan keilmuan eksak dengan bantuan keilmuan informatika, sehingga dengan menjamurnya pendidikan informatika sangat membantu menyelesaikan permasalahan dan aktivitas-aktivitas, sehingga hasil pekerjaan menjadi lebih efektif dan efisien.

Untuk menjadikan teknologi informasi yang inovatif dan berdaya saing 
diperlukan kesiapan berbagai komponen, diantaranya potensi mahasiswa, kualitas dosen, kualitas pembelajaran dan support dari lembaga sebagai pengambil kebijakan dalam mendukung kualitas teknologi informasi. Untuk mencapai kualitas teknologi informasi yang handal terkadang muncul berbagai permasalahan, diantaranya pemahaman dasar pemograman informatika yang dialami oleh mahasiswa sangat minim dan pemahaman potensi mahasiswa yang sulit dipetakan oleh lembaga sehingga dapat memperlambat penyusunan tugas akhir atau penelitian.

Upaya untuk menangani permasalahan tersebut adalah dengan membuat perencanaan yang tepat dengan langsung mengamati berbagai hal yang terjadi di kalangan mahasiswa dan lembaga, dengan cara menyebar lembar observasi dan lembar kuesioner sehingga permasalahan dapat diurai dan langkahlangkah penyelesaian dapat dilakukan secara bertahap. Dengan adanya latar belakang tersebut penulis tertarik untuk melakukan penelitian dengan judul "Diagnosa Statistik Pemetaan Pemahaman Bahasa Pemograman Dalam Mempersiapkan Penelitian Mahasiswa."

Berdasarkan latar belakang masalah diatas, batasan masalah dalam penelitian ini adalah bahasa pemograman yang meliputi Php, Java, C\#, C++,dan Delphi.

Rumusan masalah dalam penelitian ini adalah:

1. Bagaimana memetakan pemahaman bahasa pemograman mahasiswa, proses mendapatkan pemahaman dan penerapannya?

2. Bagaimana hubungan pemahaman bahasa pemograman terhadap peminatan penelitian atau skripsi?

3. Bagaimana hubungan pemahaman bahasa pemograman terhadap pembimbingan skripsi dan kebijakan lembaga?
Adapun tujuan penelitian ini adalah sebagai berikut :

1. Untuk cara memetakan pemahaman mahasiswa terhadap bahasa pemograman proses mendapatkan pemahaman dan penerapannya.

2. Untuk mengetahui hubungan pemahaman bahasa pemograman terhadap peminatan penelitian atau skripsi.

3. Untuk hubungan pemahaman bahasa pemograman terhadap pembimbingan skripsi dan kebijakan lembaga.

Adapun manfaat dari penelitian ini adalah sebagai berikut:

1. Bagi mahasiswa, untuk memetakan kemampuan bahasa pemograman sehingga mempermudah dalam penyusunan penelitian.

2. Bagi dosen, untuk masukan dan arahan tentang topik yang diangkat dalam penelitian sesuai pembimbingannya.

3. Bagi lembaga, untuk menambah masukan dan referensi dalam memutuskan arah kebijakan dari tiap program studi dalam mempercepat proses penelitian.

Untuk mengetahui tentang kejelasan dari setiap variabel penelitian, berikut dikemukakan definisi berdasarkan beberapa referensi sebagai berikut:

\section{A. Pemahaman Bahasa Pemograman}

bahasa pemrograman atau dikenal juga bahasa komputer adalah himpunan dari aturan sintaks dan semantic yang digunakan untuk mendefinisikan program komputer. Kegunaan/ Tujuan dari pemrograman adalah untuk mengisi suatu program yang dapat melakukan suatu perhitungan atau pekerjaan sesuai dengan keinginan pembuat program.

Berikut ini adalah Penggolongan bahasa pemrograman komputer berdasarkan tingkat kedekatan bahasa dengan mesin komputer.

a. Bahasa Mesin, yaitu bahasa pemrograman yang menggunakan 
bahasa biner yang terdiri dari angka 1 dan 0 untuk memberikan perintah pada komputer. Contoh : 01100101100110

b. Bahasa Tingkat Rendah, atau lebih dikenal dengan bahasa rakitan ( Assembly ). Bahasa pemrograman ini memberikan perintah pada komputer menggunakan kode-kode yang singkat ( Kode Mnemonic ), Contoh : SUB, MOV, JMP, JGE, CMP,LOOP, JL, dsb.

c. Bahasa Tingkat Menengah, yaitu bahasa pemrograman yang menggunakan campuran intruksi/ perintah dalam kata-kata bahasa manusia.

d. Bahasa Tingkat Tinggi, bahasa pemrograman yang sudah memakai instruksi dari kata-kata bahasa manusia, contoh : if, else, true, false, end, or, xor, while, dan masih banyak lagi. Sebagian besar bahasa pemrograman saat ini digolongkan sebagai bahasa tingkat tinggi.

Selain penggolongan di atas, bahasa pemograman di bagi menjadi berbagai jenis diantaranya:

a. Bahasa Pemrograman C ( Tingkat Tinggi )

Bahasa yang diperuntukkan memprogram jaringan dan sistem komputer, namun bahasa ini sering juga digunakan dalam pengembangan software aplikasi. Bahasa $\mathrm{C}$ ini juga banyak dipakai oleh berbagai jenis platform sistem operasi dan arsitektur komputer. Bahkan sudah banyak compiler populer yang sudah tersedia untuk bahasa ini.

b. Bahasa Pemrograman ASP

ASP ( Active Server Pages ) adalah bahasa pemrograman yang digunakan untuk menciptakan program web yang dinamis. ASP merupakan salah satu produk teknologi yang disediakan oleh Microsoft. ASP bekerja pada server web dan merupakan server side scripting.

c. Bahasa Pemrograman PHP ( Tingkat Tinggi )

PHP pertamakali diciptakan oleh Rasmus Lerdorf pada tahun 1995, Waktu itu PHP masih bernama Form Interpreted ( FI ), yang bentuknya berupa sekumpulan kode yang digunakan untuk mengolah bentuk data ( data form ) dari web. Seperti ASP, PHP merupakan server side scripting yang bekerja pada server web.

d. Bahasa Pemrograman Basic ( Tingkat Tinggi )

BASIC atau Begginer's All- purpose Symbolic Instruction Code pertamakali dikembangkan pada tahun 1963 oleh John George Kemeny dan Thomas Eugene Kurtz. Bahasa Pemrograman Basic mirip dengan bahasa inggris biasa yang sering digunakan oleh pemrogram dalam menulis berbagai program komputer sederhana yang berfungsi sebagai konsep dasar bagi pembelajaran pemrograman komputer.

e. Microsoft Visual Basic (Tingkat Tinggi)

Visual Basic atau lebih dikenal dengan VB adalah sebuah bahasa pemrograman yang menawarkan Integrated Development Environtmen ( IDE ) visual untuk membuat program software berbasis OS Microsoft Windows dengan menggunakan model pemrograman ( COM ). VB menawarkan pengembangan software komputer berbasis grafik dengan cepat, Visual Basic merupakan perkembangan dari bahasa pemrograman BASIC.

f. Bahasa Pemrograman JAVA ( Tingkat Tinggi )

Java adalah bahasa pemrograman yang dapat dijalankan di berbagai komputer dan telepon genggam. 
Pemrograman Java bersifat nonspesifik/ umum ( general purpose ) dan secara khusus didesain untuk memanfaatkan dependensi implementasi seminimal mungkin. Bahasa ini pertama kali dibuat oleh James Gosling dan dirilis tahun 1995.

g. Bahasa Pemrograman JavaScript ( Tingkat Tinggi )

Berbeda dengan Bahasa JAVA, JavaScrip ini adalah bahasa scripting yang berjalan pada sisi client. Bahasa pemrograman ini dikembangkan oleh Netscape. JavaScript sering digunakan untuk pembangunan web browser.

h. Bahasa Pemrograman PYTHON

Bahasa Pemrograman Python digunakan untuk berbagai macam keperluan pengembangan software ( perangkat lunak ) dan dapat bahasa ini juga bisa dijalankan di berbagai macam platform sistem operasi seperti Windows, Linux, Apple, dll.

i. Bahasa Pemrograman RUBY

Ruby adalah bahasa pemrograman yang berorientasi obyek. Tujuan dari RUBY adalah menggabungkan kelebihan dari semua bahasa pemrograma scripting yang ada di dunia. Ruby ditulis dengan bahasa pemrograman $\mathrm{C}$ dengan kemampuan dasar menyerupai Perl dan Python.

j. Bahasa Pemrograman ColdFusion

ColdFusion adalah server aplikasi dan framework pengembangan software yang digunakan untuk mengembangkan software komputer, khususnya pada situs web dinamis.

k. Bahasa Pemrograman SQL ( Tingkat Tinggi )

SQL atau kependekan dari Structured Query Language adalah bahasa pemrograman yang digunakan untuk mengakses data dalam basis data relasional. Bahasa ini secara umumnya dijadikan menjadi bahasa standar yang digunakan dalam manajemen basis data relasional.
Sekarang ini, hampir semua server basis data yang mendukung SQL untuk melakukan manajemen datanya.

1. Bahasa Pemrograman HTML ( Tingkat Tinggi )

HTML ( Hypert Text Markup Language ) adalah bahasa markah yang digunakan untuk membuat sebuah halaman website dan menampilkan berbagai informasi seperti tulisan di dalam sebuah web browser internet.

m. Bahasa Pemrograman CSS

CSS ( Cascading Style Sheet ) adalah bahasa yang digunakan untuk mengatur tampilan suatu dokumen yang ditulis dalam bahasa markah ( markup ). Umumnya sering CSS digunakan untuk memformat atau memodifikasi halaman web yang ditulis dengan HTML dan XHTML. Tapi, bahasa ini juga dapat digunakan untuk semua jenis dokumen XML termasuk XUL dan SVG. Spesifikiasi CSS diatur oleh W3C ( World Wide Web Consortium ).

n. Bahasa Pemrograman Perl

Bahasa pemrograman perl mirip dengan bahasa C. Perl digunakan untuk mesin dengan Sistem Operasi UNIX ( BSD, Linux, SunOS, HP-UX ). Perl juga tersedia untuk sistem operasi seperti Windows, DOS, VMS, EBCDIC, PocketPC, BeOS, dan PowerPC.

o. Bahasa Pemrograman Delphi Tingkat Tinggi )

Biasanya delphi lebih sering digunakan untuk pengembangan aplikasi desktop dan enterprise database, tetapi sebagai sebagai perangkat pengembangan yang bersifat umum ( general purpose ), delphi juga dapat digunakan dalam berbagai jenis proyek pengembangan perangkat lunak. 


\section{B. Peminatan Penelitian}

Roadmap Penelitian dibagi berdasarkan peminatan dan kompetensi di program studi adalah sebagai berikut:

\section{a. Computer Network and Data Security Research Group}

Adalah research group yang memiliki kemampuan dan pengetahuan dalam membuat, memelihara dan memecahkan masalah serta keamanan data pada LAN [local area network], komputer dan server

b. Software Engineering Research Group

Adalah research group yang memiliki pengetahuan dan keterampilan pengembangan dan penerapan metodologi pembuatan perangkat lunak dengan kualitas prima.

c. Web Development \& Komputasi Mobile Application Research Group Adalah research group yang memiliki keterampilan dan pengetahuan dalam membuat aplikasi terutama untuk www. Aplikasi yang memanfaatkan server dan klien (web browser) serta pengembangan aplikasi berbasis mobile yang mencakup bidang ilmu Rekayasa Web, Semantik Web, Web Service, Teknologi Web 2.0, Pemrograman Piranti Mobile, Jaringan Nirkabel, Aplikasi Web Mobile, Aplikasi Mobile

d. Sains Komputasional.

Adalah research group yang mempelajari algoritma pemodelan matematika yang diimplementasikan dalam program sains computer yang mencakup bidang ilmu pemodelan \& simulasi, Artificial Intelligence, Computer Graphics, Image Processing, Pattern Recognition dan Text Processing.

\section{Pembahasan}

Populasi menurut Arikunto (2002: 108) adalah keseluruhan subyek penelitian. Yang dijadikan populasi dalam penelitian ini adalah mahasiswa Angkatan 2014 semester 8 Fakultas Ilmu Komputer Universitas Kuningan. Teknik Pengambilan sampel dilakukan dengan Random Sampling yaitu teknik penentuan sampel dengan cara acak sesuai proporsi dari jumlah populasi. Berdasarkan hasil Random Sampling didapatkan jumlah sampel sebanyak 30 mahasiswa.

Metode yang digunakan dalam penelitian ini adalah metode campuran (mixmethode) dengan kolaborasi antara variabel kuantitatif dengan variabel kualitatif.

Teknik analisis data dilakukan berdasarkan rumusan masalah. analisis tersebut adalah sebagai berikut:

1. Untuk Menganalisis memetakan pemahaman bahasa pemograman mahasiswa, proses mendapatkan pemahaman dan penerapannya maka dilakukan analisis kuesioner dalam skala likert dengan menggunakan bantuan software.

2. Untuk Menganalisis hubungan pemahaman bahasa pemograman terhadap peminatan penelitian atau skripsi maka dilakukan analisis kuesioner dalam skala likert dengan menggunakan bantuan software.

3. Untuk Menganalisis hubungan pemahaman bahasa pemograman terhadap pembimbingan skripsi dan kebijakan lembaga maka dilakukan analisis kuesioner dalam skala likert dengan menggunakan bantuan software.

Data-data yang telah diuraikan di atas mayoritas memiliki respon yang baik yaitu setuju dan sangat setuju. Agar hasil pengolahan kuesioner dapat dihubungkan dengan keterkaitan dari masing-masing 
variabel, maka saya susun dalam ringkasan sebagai berikut.

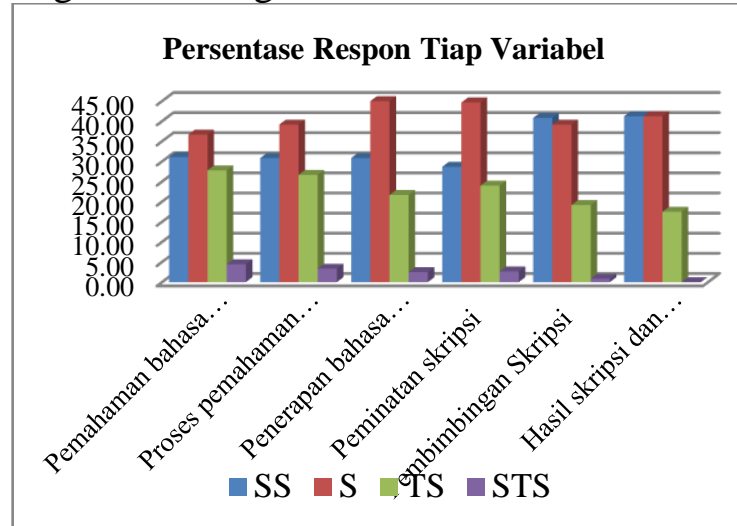

\section{Grafik 4.7 Persentase Respon Tiap Variabel Pengukuran}

Dari grafik di atas tiap variabel memiliki respon setuju dan sangat setuju paling tinggi sehingga dapat disimpulkan sebagian mahasiswa merasakan adanya hubungan bahasa pemograman yang dipahami terhadap variabel variabel lain. Untuk lebih jelas ditampilkan juga dalam bentuk tabel berikut

Tabel. 4.1 Hasil Kuesioner Tiap Variabel Pengukuran

\begin{tabular}{|c|c|c|c|c|c|c|c|}
\hline \multirow{2}{*}{$\begin{array}{l}\mathrm{N} \\
\mathrm{o}\end{array}$} & \multirow{2}{*}{$\begin{array}{c}\text { Variabel } \\
\text { Pengukuran }\end{array}$} & \multicolumn{4}{|c|}{$\begin{array}{l}\text { Persentase } \\
\text { Respon }\end{array}$} & \multicolumn{2}{|c|}{$\begin{array}{l}\text { Persent } \\
\text { ase } \\
\text { Katego } \\
\text { ri }\end{array}$} \\
\hline & & $\begin{array}{l}\mathrm{S} \\
\mathrm{S}\end{array}$ & $\mathrm{S}$ & $\begin{array}{l}\mathrm{T} \\
\mathrm{S}\end{array}$ & $S$ & $\begin{array}{l}\mathrm{P} \\
\text { os } \\
\text { iti } \\
\mathrm{f}\end{array}$ & $\begin{array}{l}\mathrm{N} \\
\mathrm{eg} \\
\text { ati } \\
\mathrm{f}\end{array}$ \\
\hline 1 & $\begin{array}{l}\text { Pemahaman } \\
\text { bahasa } \\
\text { pemograman } \\
\text { mahasiswa }\end{array}$ & $\begin{array}{l}\text { 1 } \\
1\end{array}$ & $\begin{array}{l}3 \\
6 \\
6 \\
6 \\
7\end{array}$ & $\begin{array}{l}2 \\
7 \\
7 \\
7 \\
8\end{array}$ & $\begin{array}{l}4 \\
4\end{array}$ & $\begin{array}{l}67 \\
, 7 \\
8\end{array}$ & $\begin{array}{l}32 \\
2 \\
2\end{array}$ \\
\hline 2 & $\begin{array}{l}\text { Proses } \\
\text { pemahaman } \\
\text { bahasa } \\
\text { pemograman }\end{array}$ & $\begin{array}{l}3 \\
0\end{array}$ & $\begin{array}{l}3 \\
9 \\
1 \\
1 \\
7\end{array}$ & $\begin{array}{l}2 \\
6\end{array}$ & 3 & $\begin{array}{l}70 \\
, 0 \\
0\end{array}$ & $\begin{array}{c}30 \\
, 0 \\
0\end{array}$ \\
\hline 3 & $\begin{array}{l}\text { Penerapan } \\
\text { bahasa } \\
\text { pemograman }\end{array}$ & $\begin{array}{l}3 \\
0\end{array}$ & $\begin{array}{l}4 \\
5\end{array}$ & $\begin{array}{l}2 \\
1\end{array}$ & 2 & $\begin{array}{l}75 \\
, 8 \\
3\end{array}$ & $\begin{array}{c}24 \\
, 1 \\
7\end{array}$ \\
\hline
\end{tabular}

\begin{tabular}{|c|c|c|c|c|c|c|c|}
\hline 4 & $\begin{array}{l}\text { Peminatan } \\
\text { skripsi }\end{array}$ & $\begin{array}{l}2 \\
8 \\
6 \\
6 \\
7 \\
\end{array}$ & $\begin{array}{l}4 \\
4 \\
\\
6 \\
7 \\
\end{array}$ & $\begin{array}{l}2 \\
4 \\
, \\
0 \\
0\end{array}$ & $\begin{array}{l}2 \\
6 \\
6 \\
7\end{array}$ & $\begin{array}{c}73 \\
, 3 \\
3\end{array}$ & $\begin{array}{c}26 \\
, 6 \\
7\end{array}$ \\
\hline 5 & $\begin{array}{l}\text { Pembimbing } \\
\text { an Skripsi }\end{array}$ & $\begin{array}{l}4 \\
0 \\
, \\
8 \\
3 \\
\end{array}$ & $\begin{array}{l}3 \\
9 \\
, \\
1 \\
7\end{array}$ & $\begin{array}{l}1 \\
9 \\
, \\
1 \\
7\end{array}$ & $\begin{array}{l}0 \\
, \\
8 \\
3\end{array}$ & $\begin{array}{c}80 \\
, 0 \\
0\end{array}$ & $\begin{array}{c}20 \\
, 0 \\
0\end{array}$ \\
\hline 6 & $\begin{array}{l}\text { Hasil skripsi } \\
\text { dan } \\
\text { kebijakan } \\
\text { lembaga }\end{array}$ & $\begin{array}{l}4 \\
1 \\
2 \\
2 \\
5\end{array}$ & $\begin{array}{l}4 \\
1 \\
2 \\
5\end{array}$ & $\begin{array}{l}1 \\
7 \\
5 \\
5\end{array}$ & 0 & $\begin{array}{c}82 \\
, 5 \\
0\end{array}$ & $\begin{array}{l}17 \\
, 5 \\
0\end{array}$ \\
\hline & $\begin{array}{l}\text { Rata-rata } \\
\text { Persentase }\end{array}$ & $\begin{array}{l}9 \\
9 \\
2\end{array}$ & $\begin{array}{l}4 \\
0 \\
9 \\
9 \\
9\end{array}$ & $\begin{array}{l}2 \\
2 \\
, \\
8 \\
0 \\
\end{array}$ & $\begin{array}{l}2 \\
, \\
3 \\
0\end{array}$ & $\begin{array}{c}74 \\
, 9 \\
1\end{array}$ & $\begin{array}{c}25 \\
, 0 \\
9\end{array}$ \\
\hline
\end{tabular}

Dari Tabel di atas, terlihat bahwa persentase kategori positip (jumlah respon setuju dan sangat setuju) dari tiap variabel lebih dari 50\%, sedangkan persentase kategori negatif (jumlah respon tidak setuju dan sangat tidak setuju) dari tiap variabel kurang dari $50 \%$, maka dapat disimpulkan bahwa penguasaan bahasa pemograman berpengaruh terhadap proses pemahaman, penerapanya dan terhadap peminatan skripsi yang disusunnya. Data rata-rata persentase respon tiap variabel pengukuran menunjukan kategori positif sebesar 74,91\%. Hal ini merupakan suatu prestasi yang biasa karena masih ada kategori negatif sebesar 25,09\% yang harus diperbaiki. Upaya perbaikan untuk meningkatkan respon positif yaitu dari mulai mendeteksi pemahaman bahasa pemograman pada pembelajaran dikelas maupun pada tugas-tugas projek tertentu yang bertujuan mengasah kemampuan pemahaman bahasa pemograman mahasiswa. Sehingga pada saat penyusunan skripsi program studi dan dosen pembimbing mampu memetakan 
kekurangan dan kelebihan pemahaman bahasa pemograman mahasiswa. Dengan adanya pemetaan ini akan memperlancar mahasiswa agar lulus tepat waktu, meningkatkan produktivitas mahasiswa dan meningkatkan kualitas mahasiswa lulusan untuk memiliki daya saing tinggi.

\section{Kesimpulan}

Berdasarkan rumusan masalah, hipotesis, analisis data dan pembahasan yang telah dipaparkan, maka dapat disimpulkan sebagai berikut.

1. Adanya pemetaan pemahaman bahasa pemograman mahasiswa, proses mendapatkan pemahaman dan penerapannya pada tugas projek dan skripsi.

2. Adanya hubungan pemahaman bahasa pemograman terhadap peminatan penelitian atau skripsi.

3. Adanya hubungan pemahaman bahasa pemograman terhadap pembimbingan skripsi dan kebijakan lembaga.

Mengacu pada hasil penelitian yang telah diuraikan, maka penulis memberikan saran sebagai berikut.

1. Bagi Lembaga, dengan adanya hasil penelitian ini diharapkan dapat memberikan pemetaan pemahaman bahasa pemograman mahasiswa sehingga pihak lembaga dapat mempasilitasi produk skripsi mahasiswa untuk didaftarkan ke HAKI dan dimuat pada jurnal sehingga akan menaikan akreditasi lembaga.

2. Bagi Dosen, dengan adanya hasil penelitian ini diharapkan memberikan motivasi dan referensi dalam membimbing skripsi dan mengembangkan penelitian dosen.

3. Bagi Mahasiswa, dengan adanya hasil penelitian ini diharapkan dapat memberikan motivasi dalam penguasaan matakuliah khususnya bahasa pemograman agar dapat lulus dengan tepat waktu dan memberikan suatu produk dari skripsi untuk dimanfaatkan oleh mahasiswa yang lain dan meningkatkan kualitas lulusan yang berdaya saing.

Daftar Pustaka

Arikunto, S. (2002). Prosedur Penelitian. Jakarta: Rineka Cipta.

Sugiyono, (2010). Metode Penelitian Pendidikan, Bandung: Alfabeta. 